\section{Institutional Barriers to Increasing Representation of Women in Canadian Government}

Natasha Mukhtar

Queen's University

An important function of Canadian political institutions is the task of representation. Ideally, the different arenas of a democratic government which make important policy decisions regarding the population should mirror its constituents. Yet, women, who comprise half of Canada's population, are far outnumbered by men in important policy sectors such as the House of Commons and Cabinet. This "democratic deficit" of underrepresentation will be the focus of this paper (Trimble $\&$ Arscott 2008, 3). This paper will investigate how women are underrepresented in terms of employment in Canadian government. Specifically, this paper will argue that Canadian institutions are constrained in their effort to represent women and require the implementation of institutional reform. This paper will define greater representation of women as greater employment in government and the formal decision-making process. This paper will explain constraints of institutions by examining efforts and their inability to enforce employment and pay equity for women in order to encourage their involvement in government. These past efforts, this paper argues, faced fundamental institutional barriers of party pressures, lack of specificity, and difficulties in passing legislation which limited their potential success. Institutional reform in the form of lessening such internal constraints is needed to help pass legislation to increase representation of women and decrease the democratic deficit on a larger scale.

This paper will begin by indicating the lack of women in higher levels of government. It will expand on the barriers they face to demonstrate the need for greater representation. It will then give a brief overview of two strategies aimed at increasing representation: pay and employment equity measures employed by institutions in the past. Instead of focusing on the social movements and cultural shifts towards the employment of women, this paper will focus primarily on these direct initiatives of Canadian institutions. These strategies and their failure to increase women in government to mirror population demographics will be analyzed. This paper will then demonstrate that a broader institutional problem is at fault for the relative unsuccessfulness of these policies. This paper will argue that this larger issue urges the need for institutional reform.
To understand the need for investigating the underrepresentation of women in Canadian government, it is necessary to examine certain pertinent facts. Women constitute nearly 52 percent of the Canadian population and about as much of the electorate (Brooks 2009, 424). Though women slightly outnumber men in the population, they continue to be a minority in the government. Few women have held the highest positions in provincial and federal governments; the number of which can be counted on the fingers of two hands (Brooks 2009, 424). Women constitute 20 percent of members in the House of Commons ("Women: Federal Political Representation" 2010, para. 1). The House, representing the bulk of Canadian Parliament, is recognized as housing the dominant legislative chamber in the federal government and is expected to represent different ridings, and thus constituents, across the provinces ("Women: Federal Political Representation" 2010, para. 1). Low levels of women are particularly apparent in high levels of government. This observation is what Bashevkin terms, the "higher the fewer" (Bashevkin 2009, 4). By this, Bashevkin means that the higher one goes in the levels of government, the fewer women one sees. This demonstrates that a fundamental crisis is apparent in Canadian government. Little more than half the population of a democratically governed society is disproportionately represented by a small minority employed in the main decision making office. Legitimacy and representational functions of government institutions appear unfulfilled and a shortage in Canadian democracy thus becomes apparent.

While women are generally underrepresented in Canadian government, major strides have been made by political decisions to increase women's political employment in the past. From the 1970s to the year 2007, the number of women in Ontario legislatures peaked in the 1990s (Bashevkin 2009, 95). This marked a high point in the representation of women in government likely due to a combination of feminist social movements and political decisions. The latter consisted of policies passed by the Ontario New Democratic Party (NDP). Affirmative action legislation, requiring the improvement in the representation of women in internal party bodies, was enacted in 1982 (Bashevkin 2009, 94). The party also demanded a focus on the nomination of candidates from minority target groups which included women. As a result, the NDP nominated a record number of women candidates in 1990 (Bashevkin 20009, 95). Other awareness activities about the need to employ more women in political bodies were conducted and various provisions, such as child care expenses, were provided by the NDP to further encourage women to become politically active (Bashevkin 2009, 95). When the NDP gained power in 1990, it brought a striking number of women into Parliament (Bashevkin 2009, 96). It is not 
surprising that just a few years later these successes resulted in the election of the first female Prime Minister, Kim Campbell and an unprecedented amount of women in the House of Commons (Tremblay \& Andrew 1998, 221). These strides justify the need for political decision making bodies to actively introduce political measures enforcing greater representation of women.

These measures, however, did not succeed in eliminating all systemic barriers to women's political employment in Canada. Bashevkin recognizes that certain "stage" barriers to women's involvement in political office still exist (Bashevkin 2009, 108). These barriers take the form of the actual political environment or structural barriers in government which hurt democratic representation. The stage of politics in Canada is one in which certain electoral rules, policies, and party conditions make it difficult for women to become active in political office. From this, it can be interpreted that the current stage or rules of the game of Canadian politics inhibit representation of women. This points to a larger systemic problem of Canadian institutions which fail to fulfill their democratic role of representation. These rules or conventions include that fact that parties in power are less likely to recruit women, or that women do better in political environments of less competition (Bashevkin 2009, 109). The rules or measures which Bashevkin calls for to alleviate the hostility towards women in the political environment consist of a non-adversarial political stage in which egalitarian, left-wing parties who have good relations with feminist groups are in power (Ibid, 109). These conditions create the ideal environment for women to strive in politics. With the opposite of these conditions currently in effect, women face structural stage barriers to political employment. By this scenario, the capacity for representation of women depends on a change in the rules of the game, that is, in the current rules and conventions of Canadian political institutions. The rules of current game of Canadian politics are unfair and undemocratic (Paxton \& Hughes 2007, 8). This necessitates a change or reform in the rules of the game, or in the running of Canadian institutions.

Clement addresses specific institutional political decisions which have further entrenched a hostile political environment for women in Canada. While Canadian efforts to increase representation of women in the decision making process appeared to peak just before the 1990s, these initiatives saw a decline from then on. Clement argues this shift in focus from the issue of women's representation was issuing from a shift in policy (Clement 2008, 107). A dramatic change in Canada's party ordering system saw the Conservatives gaining power in Parliament in the 1990s (Tremblay \& Andrew 1998, 222). Once in power, they eliminated funding to

Vol. 13 Federalism-E women's organizations such as the National Action Committee on the Status of Women which advocated increased involvement in public life (Clement 2008, 108). Additionally, a $\$ 5$ billion daycare program was rejected by legislation (Clement 2008, 108). A new stage was set, empowering a right-wing party with evidently no interest in maintaining good relations with feminist organizations or their cause. It seemed the rules of the game were being tweaked, though not in favour of women. As Clement argues, this shift proved the claim that barriers to women's employment in Canadian government stemmed from systemic problems (Ibid, 107).

In the past twenty years, Canadian political institutions have devised various policies to increase the number of women in government. These employment strategies were meant to enforce greater gender equality and thus representation in government. Of these strategies, pay and employment equity measures in particular have an ability to promote greater representation in political office by increasing the quality of work for women (Tremblay \& Andrew 1998, 85). In terms of pay equity, legislation for equal pay of equal value was passed federally and provincially in the 1950s and included in the 1971 Canada Labour Code (Tremblay \& Andrew 1998, 91). However, the legislation passed was innately flawed by vagueness surrounding the definition of equal value which made complaints difficult to file as few ever were (Tremblay \& Andrew 1998, 92). Yet, this vagueness was fundamental to its passing as catering to many interests, provincial and federal, inherently reduces the complexity of most issues targeted by legislation until only a bare bones of the intended policy is left. That seems the only way to get such a, at the time, radical policy passed in a federalist system which requires agreements of many different governments. Employment equity for women was targeted by the Canadian Human Rights Act in 1977 and the Charter in 1982 meant to eliminate discrimination in recruitment based on identity (Tremblay \& Andrew 1998, 92). Like the pay equity legislation, these all-encompassing measures lacked a clear mandate and proved logistically impossible to enforce (Tremblay \& Andrew 1998, 93). Other measures, such as childcare and maternity leave may also facilitate employment of women, though these have difficulty passing through legislation due to party pressures, budget issues, and other institutional constraints. For example, as mentioned before, childcare plans were rejected by the Conservative government during the 1990s likely due to pressures from party leaders adamant on keeping with the original party stance against such costly pro-women's employment measures. Though these measures appeared forward-thinking on the issue of women's employment, they stand as examples of how institutional constraints can reduce the actual success of these well-meaning efforts. 
Although these measures appeared to be initially successful, women continue to constitute only 20 percent of members of the House of Commons ("Women: Federal Political Representation" 2010, para. 1). Even though formal legislation for equal employment has passed, "veiled discrimination" in recruiting women still exists (Paxton \& Hughes 2007, 3). The reason for the apparent stagnation in success of these policies can be linked to broader institutional issues and constraints. As mentioned before, this paper believes it is these constraints which perpetuate this "democratic deficit" in Canada. This deficit is defined by this paper to be in part due to the underrepresentation of women in government. As such, democracy, though notoriously hard to define, is taken to be largely a measure of how well political decision making bodies represent or mirror their constituents. In such a government, there is a greater diversity of values and ideas essential to unbiased democratic decision making (Paxton \& Hughes 2007, 14). Naturally, it is expected that half of the population of a country not be underrepresented in a democratic government. Some may argue that even the election or employment of women may not increase the number of politicians striving for and supporting women's issues. However, it would still increase the diversity of ideas and policies debated by governmental institutions, thus enhancing democracy. Though measures to eliminate this deficit, such as the 1982 Charter of Rights and 1971 Labour Code have been implemented, there continues to be a discrepancy or "glass ceiling" between their intended effects and real world potential of achieving those (Trimble \& Arscott, 2008 3). Sometimes, it seems, these measures themselves stagnate efforts to increase representation. This may be due to the institutions designing and implementing as well as their sheer vagueness and indirectness in addressing issues. This is why this paper argues for broader institutional reform or lessening of constraints on institutions to more effectively pass legislation targeting the underrepresentation of women.

Institutional reform can consist of simply less constraints on institutions, such as the courts or legislature, when they attempt to pass bills or policies that will help solve widely agreed upon challenges to democracy in Canada. In this sense, it is not a complete restructuring of the political system or even radically different employment policies which must be adopted to increase representation of women. Instead, this paper recognizes the potential of past policies in attempting to bridge the gap between numbers of men and women in government. It argues that these policies had some impact, but were restrained in their effectiveness because of the way institutions were required to design them. Legislation and reports tackling the issue of underrepresentation of women are often made to be a small part of larger, and thus vaguer, bills meant to solve too many ills in one time. This may be because other similar anti-discrimination efforts are often combined with women's legislation in, for example, the Charter and Labour Code. Passing separate, more clarified and in depth legislation for each cause seems too difficult and vulnerable to opposition. It is for these reasons that this paper argues for less constraints on institutions when passing legislation for pro-democratic efforts, such as those to increase the representation and employment of women in government.

In conclusion, the current situation in Canadian political institutions is one which contributes to a discrepancy in democratic government. This discrepancy is the continued underrepresentation, in the form of employment, of women in government. The current rules of the game, it appears, perpetuate this inequality between men and women. Though strategies to increase female employment such as pay and employment equity have made some impact, they appear to have stagnated in their success in recent years. This is proven by the continued low numbers of women in government. This persistence points to a larger systemic problem in Canadian government, recognized by this paper as the constraints around decision making institutions. Policies to fight discrimination are often vague and indirect when passed and remain difficult to enforce as a result. This indicates that there is a need for institutional reform in Canadian government, specifically, a lessening of internal constraints. 


\section{Bibliography}

Arscott, Jane, and Linda Trimble. In the Presence of Women: Representation in Canadian Governments. Toronto: Harcourt Brace, 1997.

Bashevkin, Sylvia, ed. Opening Doors Wider: Women's Political Engagement in Canada. Vancouver: U of British Columbia P, 2009.

Brooks, Stephen. Canadian Democracy. 6th ed. Don Mills, ON: Oxford UP, 2009.

Clement, Dominique. "I Believe in Human Rights, Not Women's Rights": Women and the Human Rights State, 1969 - 1984.” Radical History Review. 101 (2008): 107-129.

Paxton, Pamela, and Melanie M. Hughes. Women, Politics, and Power: A Global Perspective. Los Angeles: Pine Forge Press, 2007.

Tremblay, Manon, and Caroline Andrew, eds. Women and Political Representation in Canada. Ottawa: U of Ottawa P, 1998.

Trimble, Linda, and Jane Arscott. Still Counting: Women in Politics Across Canada. 2nd ed. Toronto: U of Toronto P, 2008.

“Women: Federal Political Representation.” Parliament of Canada. 30 April 2010. 28 March

2011.<http://www2.parl.gc.ca/Parlinfo/compilations/parliament/WomenRepres entation. aspx ?Language $=\mathrm{E} \& \mathrm{Menu}=\mathrm{HOC}$ -

Representation\&Parliament=0d5d5236-70f0-4a7e-8c96-68f985128af9> . 